\title{
Analysing lawyers' attitude towards knowledge sharing
}

\author{
Authors: \\ Wole M. Olatokun ${ }^{1}$ \\ Isioma N. Elueze ${ }^{1}$ \\ Affiliations: \\ ${ }^{1}$ Africa Regional Centre for \\ Information Science (ARCIS), \\ University of Ibadan, Nigeria \\ Correspondence to: \\ Wole Olatokun \\ Email: \\ woleabbeyolatokun@yahoo. \\ co.uk \\ Postal address: \\ PO Box 22133, University of \\ Ibadan, Nigeria \\ Dates: \\ Received: 31 Oct. 2011 \\ Accepted: 09 June 2012 \\ Published: 17 Sept. 2012 \\ Republished: 28 Mar. 2013 \\ How to cite this article: \\ Olatokun, W.M. \& Elueze, \\ N.I., 2012, 'Analysing lawyers' \\ attitude towards knowledge \\ sharing', SA Journal of \\ Information Management \\ 14(1), Art. \#507, 11 pages. \\ http://dx.doi.org/10.4102/ \\ sajim.v14i1.507 \\ Note: \\ This article has been \\ republished with the \\ updated initials of the \\ author: I.N. Elueze.
}

(C) 2012. The Authors. Licensee: AOSIS OpenJournals. This work is licensed under the Creative Commons Attribution License.
Objectives: The study examined and identified the factors that affect lawyers' attitudes to knowledge sharing, and their knowledge sharing behaviour. Specifically, it investigated the relationship between the salient beliefs affecting the knowledge sharing attitude of lawyers', and applied a modified version of the Theory of Reasoned Action (TRA) in the knowledge sharing context, to predict how these factors affect their knowledge sharing behaviour.

Method: A field survey of 273 lawyers was carried out, using questionnaire for data collection. Collected data on all variables were structured into grouped frequency distributions. Principal Component Factor Analysis was applied to reduce the constructs and Simple Regression was applied to test the hypotheses. These were tested at $0.05 \%$ level of significance.

Results: Results showed that expected associations and contributions were the major determinants of lawyers' attitudes towards knowledge sharing. Expected reward was not significantly related to lawyers' attitudes towards knowledge sharing. A positive attitude towards knowledge sharing was found to lead to a positive intention to share knowledge, although a positive intention to share knowledge did not significantly predict a positive knowledge sharing behaviour. The level of Information Technology (IT) usage was also found to significantly affect the knowledge sharing behaviour of lawyers'.

Conclusion: It was recommended that law firms in the study area should deploy more IT infrastructure and services that encourage effective knowledge sharing amongst lawyers.

\section{Introduction}

The acquisition, application, and leveraging of knowledge are important for organisations to achieve success. As the 21st century unfolds, many people regard the strategic management of knowledge resources as one of the key factors for sustainable competitive advantage. In particular, knowledge sharing is perceived to be the most essential process for knowledge management (Bock \& Kim 2002). Grant (1996) regards knowledge as the most strategically important resource that an organisation possesses. It forms a very important part of an organisation's core competence and it is needed to combine other production factors effectively to achieve set goals (King \& Iyoha 2008). Knowledge management comprises a range of practices applied by organisations to identify, create, represent, distribute and enable them to adopt what they know and how they know it, and these practices are tied to organisational objectives and goals. It is therefore imperative for workers in an organisation to have a constructive attitude to sharing knowledge in order for the organisation to be successful.

Lawyers are knowledge workers who engage in different types of knowledge intensive activities (Ojo \& Grand 2011). Today the legal profession faces great challenges and lawyers are permanently being flooded with new information, such as frequent changes in legislation and new court decisions, amongst many other changes (Schulz \& Klugmann 2005). Knowledge sharing in law firms is the process of distributing know-how relevant to legal practice and the success of the law firm. The theme of knowledge sharing in law firms has been discussed in some knowledge management literature that tends to highlight factors that affect knowledge sharing activity. Of these, 'attitude' has been cited as a major factor. Davenport (1997) argued that sharing knowledge is often unnatural, stating that people will not share their knowledge, and think their own knowledge is valuable and important. Some factors that could influence a person's willingness to share knowledge, have been identified including trust, promotion, incentives, rewards, motivation, relationships, incentive systems, culture, top management support, senior leadership, contribution, association, and other factors. Bircham (2003) considered that a recipient may not be willing to accept shared knowledge from others, owing to a lack of trust of the source individual. The recipient's attitude may also be influenced by how effectively knowledge has been articulated by the sender. 
Attitudes affect people in everything they do and reflect what they are hence, it is a determining factor of the behaviour of people. Also, it provides people with a framework within which to interpret the world and integrate new experiences, as noted by Ogunmoye (2008). Thus, by understanding an individual's attitude towards something, one can predict with high precision his or her overall pattern of behaviour to the object. Ogunmoye also noted that according to Aiken (2000), attitude is a learned disposition that determines a positive or negative response to a specific object, situation, institution, or a person. Therefore, attitude reflects what the individual is and, hence, it is a determining factor of the individual's attitude, and provides people with a framework within which to interpret the world and integrate new experiences (Ogunmoye 2008).

Often, attitude influences how workers interact. Argote and Ingram (2000) suggested that organisational knowledge resides in the interactions between individuals and, therefore, forms the basis of competitive advantage. It has also been noted that the future, survival or existence of any individual, organisation, society or group of people will be determined by their ability to manage and share knowledge wisely, or their effective application of knowledge, which is an essential and precious global resource that is an embodiment of human intellectual capital and technology. Knowledge management is a key law firm business driver. The typical law firm knowledge management vision is to achieve market differentiation through leveraging its knowledge (Global Law Firm Knowledge Management Survey Report 2002). A positive attitude to knowledge sharing by workers of a law organisation would help the law organisation identify its weaknesses and strengths. Senior management in many organisations understand the importance of knowledge sharing amongst their employees and are, thus, eager to introduce knowledge management paradigms (Bock \& Kim 2002). Law is a knowledge intensive industry. Fundamentally, the business of lawyers is the sale of their knowledge (Gottschalk, Brekke \& Pedersen 2005). Law organisations increasingly recognise the value of knowledge sharing and if they must capitalise on the knowledge they possess, they must understand how knowledge is created, shared, and applied within the organisation. Knowledge exists and is shared at different levels in organisations (Ipe 2003). Creating and fostering a culture of knowledge sharing is, in practice, one of the most difficult tasks when introducing a Knowledge Management system into a law firm (Eiseman 2007). According to King and Iyoha (2008):

We discovered that in Nigeria, most companies do not appreciate the importance of managing an organisation's knowledge; neither do they know the importance of expanding the organisation's knowledge base through knowledge sharing. They fail to understand the importance of knowledge sharing to sustaining an organisation's competitive advantage. (p. 9)

This study investigated the attitude of lawyers in some selected law firms in Ibadan, a Nigerian metropolis, towards knowledge sharing using the Theory of Reasoned Action model (TRA) (Azjen \& Fishbein 1980). The theory states that attitude towards a behaviour is a precursor to an individual's intention towards performing a behaviour (Bock \& Kim 2002). In the context of this study, it implies that if a worker has a favorable attitude towards sharing his or her knowledge with other workers, there is a high possibility that he or she will share available knowledge. A less favorable attitude may result in little or no knowledge being shared. As a result of the TRA having been successfully applied in some earlier studies on knowledge sharing (Bock \& Kim 2002; Ryu, Hee-Ho \& Han 2003; Gottschalk et al. 2005), the model is considered fit to guide the study. Expected reward, expected contribution, and expected association were determinants of the attitude of workers towards knowledge sharing, whilst attitude was a determinant of the workers' intention to share knowledge.

\section{Literature review \\ Knowledge sharing in organisations}

It has become a common activity within organisations to apply a variety of means to properly disseminate relevant information within their firms, in order to integrate all parts of the workforce in actualising the organisation's vision (Senge 2007). Methods, including brainstorming sessions, PowerPoint presentations and storytelling have all been part of a list of methods applied in different ways to share knowledge within the organisation. Chua (2003) defines knowledge sharing as the process by which individuals collectively and iteratively refine a thought, an idea or a suggestion in the light of their experiences. Similarly, according to Ipe (2003:340) the sharing of an individual's knowledge is imperative to the 'creation, dissemination, and management of knowledge at all other levels within an organisation'. An organisation's ability to effectively leverage its knowledge is highly dependent on its people, who actually create, share, and apply the knowledge. Leveraging knowledge is only possible when people can share their knowledge and build on the knowledge of others. Knowledge sharing is basically the act of making knowledge available to others within the organisation. Knowledge sharing between individuals is the process by which knowledge held by an individual is converted into a form that can be understood, absorbed, and applied by other individuals, that contributes to both individual and organisational learning (Ipe 2003). Knowledge sharing is important because it provides a link between the individual and the organisation by moving knowledge that resides with individuals to the organisational level, where it is converted into economic and competitive value for the organisation (Hendriks 1999). The voluntary act of an individual sharing his or her knowledge contributes to knowledge distribution, and the process of sharing may result in knowledge acquisition by other individuals within the organisation (Ipe 2003). Knowledge sharing between individuals, thus, results in individual learning, which in turn may contribute to organisational learning (Turner \& Minonne 2010). Understanding the process of knowledge sharing between individuals is one step toward a better understanding of knowledge sharing as a whole in organisations. 
Knowledge sharing is the capturing, storing and dissemination of information using appropriate media to further the development of employees and enhance the work processes. Knowledge sharing could be undertaken in many ways. It could be a mere discussion with a colleague or capturing and reusing experienced based knowledge residing within the organisation. In so doing this makes knowledge accessible to other employees. Knowledge sharing enables new knowledge to be created and also translated into innovative technologies and processes (Joseph, Firestone \& McElroy 2005). The ability to share knowledge between organisational units and departments contributes immensely to the performance of the organisation (Hendriks 2005). The process, of exchanging ideas, information and, consequently, knowledge, enables organisations to increase thier knowledge base. The reasons why organisations encourage knowledge sharing stems from the fact that much of the knowledge of organisations is controlled at the level of the individual employee (Hendriks 2005). Individuals utilise their knowledge in the course of carrying out their duties at work (Joseph et al. 2005). An organisation is bound to lose knowledge if the individual possessing it leaves the organisation, and if the organisation has not facilitated the individual sharing their knowledge with other employees (Gupta 2000). But, if the employee remains with the organisation, the organisation may not utilise the knowledge of this employee unless there are opportunities for them to share this knowledge with others in the organisation (Gupta 2000). It is worthwhile, therefore, for organisations to create an atmosphere of sharing to ensure that knowledge remains within it, notwithstanding the resignation of an employee. The individual employees must work together, share ideas, information and knowledge in order to achieve organisational aims and objectives. Organisations must understand the needs and wants of their employees to understand what triggers employees' attitude to share knowledge, their intention to share knowledge and their overall knowledge sharing behaviour. It could be promotion, job security, meeting personal needs, attending training and courses, for example. By understanding these factors organisations will further improve the knowledge sharing capabilities of their employees. Ethnicity, employee age, educational level, employee ethics, corporate culture, trust, management commitment, involvement in the organisation and an individual's perception of the organisation, have been identified in various literature as criteria that affect an employee's willingness to share knowledge in knowledge intensive organisations. Other criteria are rewards, leadership, resources provided, job title, tenure, organisational climate, contributions, power, organisational politics and IT support.

\section{Knowledge sharing in law firms}

Gottschalk et al. (2005), in their study of the Incentives for Knowledge Sharing through Information Technology, carried out in two law firms in Norway, noted that a lawyer's attitude towards their own contribution in an organisation, was the factor that most predicted their share of knowledge, followed by their attitude towards rewards. The attitude towards associations and perceived management commitment was observed to be of less importance to a lawyer's knowledge sharing behaviour in the law firm. They also noted that, on average, a lawyer's willingness to share their knowledge with colleagues was influenced by their perception of their ability to contribute to the organisation.

Gottschalk et al. (2005) observed that perceived management commitment did not influence knowledge sharing amongst the workers in the law firms. They also noted that user satisfaction and user-friendly systems were very important when trying to motivate lawyers to apply and share knowledge via an IT system, and that lawyers did not share knowledge, publish documents, reports and other useful information on the intranet, because it was too time consuming and complicated. Ojo and Grand (2011), in their study carried out to investigate the extent of IT acceptance and application of knowledge management in Botswana law organisations, established that more than half of the lawyers in Botswana use IT moderately for knowledge sharing. They revealed that most of the individual law knowledge workers use IT for knowledge management activities at a moderate to high level, for a variety of knowledge management activities in Botswana law organisations. These activities were knowledge seeking and documentation, knowledge organising and knowledge sharing. They proposed that their finding, that IT is under utilised for knowledge sharing than it should be, represented that time and effort expended on knowledge sharing was not adequately recognised and rewarded in most Botswana law organisations.

\section{Research model}

This study adopts the Theory of Reason Action (TRA) as proposed by Bock and Kim (2002). The theory describes the psychological processes that mediate observed relations between human attitudes and behaviour. It employs the variables attitude, social influence and intention to predict behaviour in specific contexts. TRA is based on the premise that intention is the main determinant of a person's actions or actual behaviour. Two constructs influence a person's behavioural intention: his or her attitude toward a particular behaviour and the subjective norm or social pressure exerted on him or her to carry out a behaviour or not. In TRA the beliefs and evaluations affecting an individual's attitude refer to what they think about the consequences that could arise from their behaviour as well as the personal evaluation of the desirability of these consequences. It proposes that intention to perform a particular behaviour is influenced by an individual's attitude toward performing the behaviour and the subjective norm held by the individual. Attitude toward behaviour is defined as 'an individual's positive or negative feelings about performing the target behaviour' (Ajzen \& Fishbein 1980:216) and subjective norm is defined as 'the person's perception that most people who are important to him think he should not perform the behaviour in question' (Ajzen \& Fishbein 1980:302). The theory proposes that behavioural and normative beliefs are the ultimate 
sources of an individual's attributes and norms. The TRA was designed to explain human behaviour in general; it could be applied to a wide variety of contexts. Agbonlahor (2005, citing Venkatesh, Morris, Davis \& Davis 2003) described TRA as 'one of the most fundamental and influential theories of human behaviour'. Also, the theory has been employed to predict a wide range of behaviours in diverse areas such as family planning, consumer behaviour, voting in American and British elections and an individual's acceptance of technology (Davis, Bagozzi \& Warshaw 1992). According to TRA, a person's performance of a specified behaviour is determined by their behhavioural intention to perform the behaviour. The intention is jointly determined by the person's attitude and subjective norm concerning the behaviour in question. A person's attitude towards a behaviour is determined by his beliefs about the consequences of performing the behaviour. A particularly helpful aspect of TRA is that it assumes all other factors influence behaviour by influencing attitude. Based on this, TRA can be a useful model for explaining the knowledge sharing behaviour in organisations. This study adopts TRA as re-modelled by (Bock \& Kim 2002). There are three factors (see Figure 1) that influence an employee's attitude towards knowledge sharing and their selected belief that they act as a facilitator to knowledge sharing. These factors are:

- expected reward

- expected contribution

- expected association amongst employees.

Based on the research model, the following hypotheses are formulated, that there is no significant relationship between:

1. 'expected rewards' and the attitude of lawyers towards knowledge sharing

2. 'expected associations' and the attitude of lawyers towards knowledge sharing

3. 'expected contribution' of lawyers to the organisation and their attitude towards knowledge sharing

4. the attitude of lawyers in Ibadan metropolis towards knowledge sharing and their intention to share knowledge

5. the intention of lawyers to share knowledge and their knowledge sharing behaviour

6. the level of IT usage of the lawyers in Ibadan metropolis and their knowledge sharing behaviour.

\section{Method}

The study utilised a survey design. The population comprised all lawyers and legal practitioners in all the registered law firms in the city of Ibadan, a Nigerian municipality. The total population of registered law firms in the city, as compiled by the Business Registration Unit of the Oyo state Ministry of Bureau and Commerce as of March, 2011, was obtained. The sample frame comprised all lawyers in selected law firms. The estimated average number of lawyers working in each law firm in Ibadan was given as $84 / 29=2.89$, which was approximately equal to three lawyers in each law firm. Given an average of three lawyers in each law firm in Ibadan, and given the number of law firms in Ibadan as 193, the sample frame was approximately 579 lawyers from which 289 (50\%) were selected as a sample, using simple random sampling technique.

\section{Data collection}

Data were collected using a structured questionnaire which was divided into five sections. Section A collected demographic data on each of the respondents. Section B elicited information about the respondent's knowledge sharing behaviour, whilst section C collected data about the respondent's intention to share knowledge. Section $\mathrm{D}$ collected data on the respondent's beliefs whilst section E collected data on the respondent's attitude to knowledge sharing. For specific variables in the questionnaire, data were collected on these according to the criteria below.

\section{Knowledge sharing behaviour}

The knowledge sharing behaviour of the lawyers was collected by measuring how frequently they shared knowledge or knowledge sources with other lawyers. A 4-point Likert scale was developed to measure these opinions from:
- 1 ('never')
- 2 ('seldom')
- 3 ('occasionally')
- 4 ('frequently').

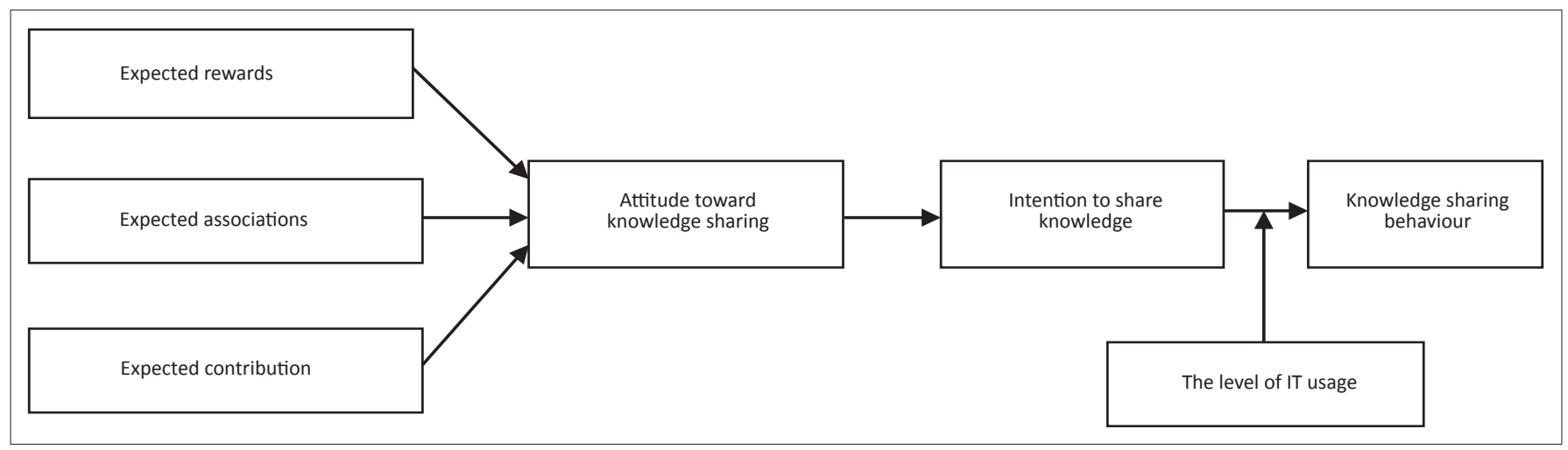

Source: Adapted from Bock, G.W. \& Kim, Y.G. 2002, 'Breaking the Myths of Rewards: An Exploratory Study of Attitudes about Knowledge Sharing', Information Resource Management Journal 15(2), 14-21. http://dx.doi.org/10.4018/irmj.2002040102

FIGURE 1: Theory of Reasoned Action. 


\section{Level of Information Technology usage}

To measure the level of usage of Information Technology (IT) services for knowledge sharing, a 4-point Likert scale was developed, from:

- 1 ('never')

- 2 ('seldom')

- 3 ('occasionally')

- 4 ('frequently').

This was intended to measure how frequently the lawyers used listed IT services to share knowledge with other lawyers.

\section{Intention to share knowledge}

To establish the intention of the lawyers to share knowledge, questions about their general intention to share knowledge with other lawyers were asked. A 5-point Likert scale was developed to measure these opinions from 1 ('strongly disagree') to 5 ('strongly agree').

\section{Expected rewards, expected associations and expected contribution}

To ascertain the individual lawyer's opinion about factors that may affect their knowledge sharing, questions were asked on their beliefs, with the following possibilities:

- of receiving rewards in return for knowledge sharing

- of changes in relationship between the lawyer and colleagues

- of the firm's improvement in its performance, as a result of the lawyer's knowledge sharing.

A 5-point Likert scale was developed to measure their responses ranging from 1 ('strongly disagree') to 5 ('strongly agree').

\section{Attitude toward knowledge sharing}

To measure the attitude of lawyers towards knowledge sharing, questions were asked about their general attitude to knowledge sharing. A 5-point Likert scale was also developed to measure their response ranging from 1 ('strongly disagree') to 5 ('strongly agree').

\section{Background information}

The demographic characteristics on which data were collected include gender, age, highest educational qualification, and length of service.

\section{Instrument validation, administration and data analysis}

Face and content validity of the instrument was carried out by researchers in the area of knowledge sharing. They thoroughly reviewed the content of the questionnaire, and the extent to which it was likely to measure the variables. It was also given to a judge of a customary court in Abuja (Nigerian Federal Capital Territory) and three other legal practitioners working in law firms in Lagos (Nigeria's commerical capital) for face validation, after which some adjustments were made to the constructs in the questionnaire. A total of 300 (numbered 001-300) copies were distributed to the lawyers in the month of May 2011. The respondents were very busy, and the major challenge experienced during the fieldwork was getting them to complete the questionnaires on time. In some cases between two and seven repeated visits were made to some law firms before the completed questionnaires could be retrieved. Out of the 300 copies administered, 281 were collected. Of these, 11 were not useable for analyses for not being properly completed. Hence, a total of 273 copies were used for data analyses.

The data collected were reduced, summarised, coded and analysed using the Statistical Package for Social Science (SPSS) software. Frequency distribution tables were generated for all the variables. The variables used to measure intention to share knowledge and the individual's beliefs and attitude to share knowledge, were recoded using a 5-point Likert scale. These were recoded as: $(1=$ strongly disagree $)+$ $(2=$ disagree $)=(1=$ disagree $),(3=$ undecided $)=(2=$ undecided $)$ and $(4=$ strongly agree $)+(5=$ agree $)=(3=$ agree $)$.

Principal component factor analysis was used to perform dimension reduction on all the constructs that made up each variable. This was performed to determine the highest loading factor, that is the constructs that are contributing the most to the variable and will best measure the variables; intention to share knowledge, the individual's beliefs and attitude to share knowledge. The aim was to bring out the few parsimonious variables that could absorb the others. Regression analysis was used to establish relationships between the independent variables and dependent variables, as stated in hypotheses 1 to hypotheses 5 . The hypotheses were tested at $0.05 \%$ level of significance.

\section{Results}

\section{Demographic characteristics of the respondents}

Males accounted for $67.8 \%$ of the respondents, whilst $32.2 \%$ were females. The largest proportion of respondents was within the age group of 21-30 years. Respondents with a degree of masters in law accounted for $22.7 .4 \%, 13.6 \%$ had a first degree in law and $57.9 \%$ had a bachelor of law degree from the Nigerian Law School. The length of service, of respondents working in the law firm, ranged from one year to 33 years, with a mean number of years of 5.98 .

\section{Knowledge sharing behaviour}

The results for the knowledge sharing behaviour of the lawyers, and their use of information technology services to share knowledge, showed that many indicated sharing the following frequently: records of court proceedings $(66.7 \%)$, judicial authorities (68.5\%), statutory authorities (67.4\%), case law $(65.6 \%)$, law reports $(65.8 \%)$, citations (51.3\%), legal trends $(46.9 \%)$, and expertise based on formal education and training $(48.0 \%)$, whilst legislative developments in law and practice notes were shared occasionally, at (44.7\%) and $(42.1 \%)$ respectively. The frequency of the use of information technology services to share knowledge by the lawyers was 
scrutinised. Results showed that most respondents reported that they occasionally share their knowledge with other lawyers with the use of email (31.1\%). However, they never shared knowledge with other lawyers via intranet $(39.2 \%)$, online forums $(44.0 \%)$, wikis $(62.3 \%)$, knowledge repositories $(31.9 \%)$ or through blogs $(65.6 \%)$, whilst they often shared knowledge with (Global System for Mobile Communication (GSM) services $(71.4 \%)$.

\section{Principal component analysis of knowledge sharing behaviour}

In order to simplify the analysis, data reduction tests were carried out on the constructs by carrying out principal factor component analysis tests, and by computing these to form a single variable called knowledge sharing behaviour. Table 1 shows a summary of the tests' results. Principal component factor analysis was applied to assess the underlying structure for the 11 knowledge sources. The Kaiser Mayer Olkin and Bartlett's test of sphericity is significant $(p=0.000<0.05)$ for all the factors. This indicates that the correlation matrix between the constructs is not an identity matrix, and the correlations between variables are therefore not all zero, thus permitting the reduction of the variable, either by the extraction or computing. Also, the determinant of correlation matrix $(0.004>0.001)$ indicates that the analysis was possible.

Judicial authorities had the highest mean value of 3.610, with a standard deviation of 0.711 , and had the highest loading factor of 0.868 with an Eigenvalue of 5.499. Relevant statutory authorities had the second highest mean value of 3.600 with a standard deviation of 0.662 and the second highest loading factor of 0.853. Expertise based on formal education and training had the second-to-lowest mean value of 3.210, which is a standard deviation of 0.927 , but had the third highest loading factor of 0.812 . Altogether these three constructs explained $74.788 \%$ of the total variance contributed by the 11 factors, and had a cumulative Eigenvalue of 8.226 out of the initial Eigenvalue of 1.0 allocated to each construct. Thus, they were computed to form a single variable to represent the higher variable knowledge sharing behaviour.

\section{Principal component analysis of intention to share knowledge}

To assess the respondents' intention to share knowledge, principal component factor analysis was also applied to examine the structure of the five identified constructs used to measure the parent variable (see Table 2).

Two components were extracted; 'I will share my knowledge with anyone in the firm if it is helpful to the law firm', and 'I intend to share my knowledge with other members in the firm more frequently in the future' had mean values of 2.870 and 2.820, and loading factors of 0.836 and 0.787 respectively. They accounted for $60.885 \%$ of the total variance explained by the five constructs, with Eigenvalues of 2.032 and 1.743. This indicated that these two factors, when computed, were sufficient to represent the variable intention to share knowledge.

\section{Principal component analysis of the individual's beliefs}

Principal component analysis was also used to reduce the constructs for the variables' expected rewards, expected associations and expected contribution into a few parsimonious constructs. The factor loading of the variables are presented in Table 3. To assess the individual's beliefs, which were factors identified as influencing the lawyers intentions to share knowledge, principal components factor analysis was applied to examine the structure of the thirteen constructs, which had already been grouped into three factors, namely, (1) expected rewards, (2) expected associations and (3) expected contribution. With $p=0.000$, the Kaiser Mayer Olkin and Bartlett test of sphericity is significant at $p<0.05$. Also, the determinant of correlation matrix gives values (0.374, 0.267 and 0.310 respectively for each variable) that are greater than 0.001 for all the three groups, indicating that the analysis is possible.

From the results in Table 3, the first factor of 'expected rewards', 'I will receive monetary rewards in return for KS' had a mean of 1.580 and a standard deviation of 0.841 . 'I will receive additional points for promotion in return for my KS' had the second highest mean value of 1.870 and a standard deviation of 0.906 , whilst 'I will receive an award, an honor or educational opportunity in return for my $\mathrm{KS}^{\prime}$ had the highest

TABLE 1: Principal component analysis of knowledge sharing behaviour.

\begin{tabular}{llll}
\hline Knowledge sharing behaviour & Mean & SD & Factor 1 \\
\hline Knowledge sources & & & \\
Records of court proceedings & 3.570 & 0.711 & 0.610 \\
Judicial authorities & 3.610 & 0.662 & $\mathbf{0 . 8 6 8}$ \\
Relevant statutory authorities & 3.600 & 0.664 & $\mathbf{0 . 8 5 3}$ \\
Case law generally & 3.560 & 0.716 & 0.782 \\
Relevant law reports & 3.570 & 0.689 & 0.712 \\
Legislative developments in the law & 3.290 & 0.764 & 0.699 \\
Relevant case notes & 3.250 & 0.843 & 0.772 \\
Citations & 3.320 & 0.841 & 0.780 \\
Practice notes & 3.010 & 0.955 & 0.705 \\
Legal trends & 3.260 & 0.856 & 0.734 \\
Expertise based on education and training & 3.210 & 0.927 & $\mathbf{0 . 8 1 2}$ \\
Analysis & & & \\
Determinant of correlation matrix & - & - & 0.004 \\
KMO and Bartlett's test (significance level) & - & - & 0.000 \\
\hline
\end{tabular}

SD, standard deviation.

Figures in bold were the highest loading factors.

TABLE 2: Principal component analysis of intention to share knowledge.

\begin{tabular}{|c|c|c|c|}
\hline Intention to share knowledge & Mean & SD & Factors 1 \\
\hline $\begin{array}{l}\text { I will share my knowledge with more members in the } \\
\text { law firm }\end{array}$ & 2.900 & 0.340 & 0.696 \\
\hline $\begin{array}{l}\text { I will always provide my knowledge at the request of } \\
\text { other members of the law firm }\end{array}$ & 2.920 & 0.333 & 0.764 \\
\hline $\begin{array}{l}\text { I intend to share my knowledge with other members } \\
\text { in the firm more frequently in the future }\end{array}$ & 2.820 & 0.510 & 0.787 \\
\hline $\begin{array}{l}\text { I try to share my knowledge with other members of } \\
\text { the firm in an effective way }\end{array}$ & 2.930 & 0.295 & 0.706 \\
\hline $\begin{array}{l}\text { I will share my knowledge with anyone in the firm if it } \\
\text { is helpful to the law firm }\end{array}$ & 2.870 & 0.456 & 0.836 \\
\hline Determinant of correlation matrix & - & - & 0.562 \\
\hline KMO and Bartlett's test (signifcance level) & - & - & 0.000 \\
\hline
\end{tabular}

$\mathrm{SD}$, standard deviation.

Figures in bold were the highest loading factors. 
mean of 1.950 and a standard deviation of 0.904 . In addition, 'I will receive additional points for promotion in return for my KS' had the highest loading factor of 0.899 and the highest proportion of variance in the observation (69.372\%). It also had an Eigenvalue of 2.081, which means that it absorbed the effect of two constructs, indicating that this variable was sufficient to represent the first group, 'expected rewards'.

'Expected associations' was the second construct; the first factor was 'KS would strengthen the tie between existing members and myself in the firm' which had a mean of 2.810, standard deviation of 0.503 , and the highest loading factor of 0.803 and accounted for $53.476 \%$ of the total variance explained. It also had an Eigenvalue of 2.674. 'Knowledge sharing would get me well-acquainted with new members in the firm' had a mean value of 2.790 , a standard deviation of 0.541 and the second best loading factor of 0.788 , and it explains $16.697 \%$ of the total variation. 'Knowledge sharing would expand the scope of my associations with other members in the firm' had a mean of 2.830 and the third highest loading factor of 0.783 . Together these three constructs accounted for a cumulative total variance of $91.296 \%$ and 4.1 of the cumulative Eigenvalues for all the factors. Thus, the three constructs were computed to obtain the variable expected associations. Although 'KS would create strong relationships with colleagues who have common interests in the firm' had the highest mean of 2.880 and the lowest standard deviation of 0.416 , it also had the lowest loading factor of 0.513 , and contributed the least to the total variance explained and had the lowest Eigenevalue ( $8.704 \%$ and 0.435 respectively).

The next factor was 'expected contribution'. 'KS would help other members in the firm to solve problems', 'KS would improve work processes in the law firm' and 'KS would increase the productivity in the firm' had equal mean scores of
2.950, with standard deviation values of $0.260,0.221$ and 0.230 respectively. 'KS would increase the productivity in the firm' had the highest loading factor of 0.803 with an Eigenevalue of 2.374 , followed by 'KS would improve work processes in the law firm', which had a loading factor of 0.787 , then 'KS would help the law firm to achieve its organisational objectives', with a loading factor of 0.716 . Together, the total variance explained by these three constructs was $82.203 \%$, indicating that computing the three variables was sufficient to represent the third group and variable expected contributions.

\section{Principal component analysis of attitude towards knowledge sharing}

Principal component factor analysis was applied to determine the potential variable that was used to represent and measure the variable attitude towards knowledge sharing. Constructs used to measure the variable include 'Knowledge sharing is good', 'Knowledge sharing is harmful', 'Knowledge sharing is an enjoyable experience', 'Knowledge sharing is valuable to me', and 'Knowledge sharing is a wise move' as shown in Table 4 .

The Kaiser Mayer Olkin and Bartlett's test of sphericity was significant and was given a value of $p=0.000$ for the factors, indicating that the correlation matrix was not an identity matrix justifying the reduction. Also, the determinant of correlation matrix gave a value $=0.284$ that was greater than 0.001 for the group, indicating that the analysis could be carried out. The results in Table 4 showed that 'Knowledge sharing is good' had the highest mean score of 2.900, whilst 'Knowledge sharing is harmful' had the lowest mean score of 1.180. However, 'Knowledge sharing is a wise move' had the highest loading factor of 0.826, with an Eigenvalue of 2.592 that accounted for $51.835 \%$ of the total variance explained. Four constructs with the highest loading factors, which

TABLE 3: Principal components analysis of the individual's beliefs.

\begin{tabular}{|c|c|c|c|c|c|}
\hline \multirow[t]{2}{*}{ The individual's beliefs } & \multirow[t]{2}{*}{ Mean } & \multirow[t]{2}{*}{ SD } & \multicolumn{3}{|c|}{ Factors (Communalities) } \\
\hline & & & 1 & 2 & 3 \\
\hline \multicolumn{6}{|l|}{ Expected rewards } \\
\hline I will receive monetary rewards in return for KS & 1.580 & 0.841 & 0.733 & - & - \\
\hline I will receive additional points for promotion in return for my KS & 1.870 & 0.906 & 0.899 & - & - \\
\hline I will receive an award, an honor or educational opportunity in return for my KS & 1.950 & 0.904 & 0.857 & - & - \\
\hline \multicolumn{6}{|l|}{ Expected associations } \\
\hline KS would strengthen the tie between existing members and myself in the firm & 2.810 & 0.503 & - & 0.803 & - \\
\hline KS would get me well-acquainted with new members in the firm & 2.790 & 0.541 & - & 0.788 & - \\
\hline KS would expand the scope of my associations with other members in the firm & 2.830 & 0.481 & - & 0.783 & - \\
\hline KS would draw smooth cooperation from outstanding colleagues in the future & 2.800 & 0.528 & - & 0.730 & - \\
\hline KS would create strong relationships with colleagues who have common interests in the firm & 2.880 & 0.416 & - & 0.513 & - \\
\hline \multicolumn{6}{|l|}{ Expected contribution } \\
\hline KS would help other members in the firm to solve problems & 2.950 & 0.260 & - & - & 0.608 \\
\hline KS would create new business opportunities for the firm & 2.700 & 0.598 & - & - & 0.477 \\
\hline KS would improve work processes in the law firm & 2.950 & 0.221 & - & - & 0.787 \\
\hline KS would increase the productivity in the firm & 2.950 & 0.230 & - & - & 0.803 \\
\hline KS sharing would help the law firm to achieve its organisational objectives & 2.920 & 0.317 & - & - & 0.716 \\
\hline \multicolumn{6}{|l|}{ Analysis } \\
\hline Determinant of correlation matrix & & & 0.374 & 0.267 & 0.310 \\
\hline KMO and Bartlett's test (signifcance level) & & & 0.000 & 0.000 & 0.000 \\
\hline
\end{tabular}


accounted for $92.090 \%$ of the total variance explained, were computed to arrive at the final variable attitude towards knowledge sharing.

\section{Test of hypotheses}

Table 5 presents the regression analysis for the test of hypotheses.

- Hypothesis 1: There is no significant relationship between expected rewards and the attitude of the lawyers towards knowledge sharing.

The results in Table 5 showed a positive and very weak correlation $(r=0.058)$. The result also indicated no significance $(p>0.05)$ in the relationship between expected rewards and attitudes towards knowledge sharing. Therefore, the null hypothesis is not rejected, that is there is no significant relationship between the lawyers' expected rewards and attitude towards knowledge sharing.

- Hypothesis 2: There is no significant relationship between expected associations and lawyers' attitudes towards knowledge sharing.

As shown in Table 5, the relationship showed a positive and strong correlation $(r=0.540)$. It also indicates a positive and significant slope $(\mathrm{B}=0.363 ; p=0.000<0.05)$. Hence, the null hypothesis is rejected, implying that there is a relationship with expected associations of lawyers in Ibadan and their attitude to sharing knowledge.

- Hypothesis 3: There is no significant relationship between the lawyers' expected contributions to the law firm and their attitudes towards knowledge sharing.

Table 5 showed that the expected contribution is significantly related $(r=0.478 ; p<0.05)$ with the attitude towards knowledge sharing, of lawyers in the Ibadan metropolis. Therefore, the null hypothesis is rejected, meaning that there is a significant relationship between expected contributions
TABLE 4: Principal component analysis of attitude towards knowledge sharing.

\begin{tabular}{llll}
\hline Attitude towards Knowledge Sharing & Mean & SD & Factor 1 \\
\hline Knowledge sharing is good & 2.900 & 0.349 & $\mathbf{0 . 7 5 4}$ \\
Knowledge sharing is harmful & 1.180 & 0.496 & $\mathbf{0 . 4 4 7}$ \\
Knowledge sharing is an enjoyable experience & 2.880 & 0.365 & $\mathbf{0 . 7 6 3}$ \\
Knowledge sharing is valuable to me & 2.870 & 0.389 & $\mathbf{0 . 7 4 7}$ \\
Knowledge sharing is a wise move & 2.880 & 0.348 & $\mathbf{0 . 8 2 6}$ \\
Determinant & - & - & 0.284 \\
KMO and Bartlett's test (sig level) & - & - & 0.000 \\
\hline
\end{tabular}

SD, standard deviation.

Figures in bold were the highest loading factors.

and attitudes towards knowledge sharing amongst lawyers in the Ibadan metropolis.

- Hypothesis 4: There is no significant relationship between the attitude of the lawyers towards knowledge sharing and their intention to share knowledge.

The results in Table 5 showed that attitude towards knowledge sharing gave a positive correlation $(r=0.156)$ with the intention to share knowledge, which was significant, at $p<0.05$. Therefore, the null hypothesis is rejected. This means that there is a significant relationship between the lawyers' attitudes towards knowledge sharing and their intention to share knowledge.

- Hypothesis 5: There is no significant relationship between the lawyers' intentions to share knowledge and their knowledge sharing behaviour.

From Table 5, the relationship between the intention to share knowledge and knowledge sharing behaviour is not significant $(r=0.084 ; p=0.165>0.05)$. Therefore, the null hypothesis is thus accepted. This implies that there is no significant relationship between intention to share knowledge and the knowledge sharing behaviour of lawyers.

- Hypothesis 6: There is no significant relationship between the level of IT services usage by the lawyers and their knowledge sharing behaviour.

TABLE 5: Regression analysis on the test of hypotheses.

\begin{tabular}{|c|c|c|c|c|c|}
\hline \multirow[t]{2}{*}{ Model } & \multicolumn{2}{|c|}{ Unstandardised coefficients } & \multicolumn{3}{|c|}{ Standardised coefficients } \\
\hline & B & SE & Beta & $t$ & Sig. \\
\hline \multicolumn{6}{|c|}{ Expected rewards and attitude towards knowledge sharing } \\
\hline 1. (Constant) & 2.842 & 0.046 & - & 62.365 & .000 \\
\hline Expected Rewards & 0.022 & 0.023 & 0.058 & 0.954 & 0.341 \\
\hline \multicolumn{6}{|c|}{ Expected association and attitude towards knowledge sharing } \\
\hline 1. (Constant) & 1.863 & 0.097 & - & 19.104 & .000 \\
\hline Expected assosciations & 0.363 & 0.034 & 0.54 & 10.573 & .000 \\
\hline \multicolumn{6}{|c|}{ Expected contribution and attitude towards knowledge sharing } \\
\hline 1. (Constant) & 0.937 & 0.218 & - & 4.306 & .000 \\
\hline Expected contribution & 0.661 & 0.074 & 0.478 & 8.965 & .000 \\
\hline \multicolumn{6}{|c|}{ Attitude towards knowledge sharing and intention to share knowledge } \\
\hline 1. (Constant) & 2.384 & 0.188 & - & 12.703 & .000 \\
\hline Attitude towards KS & 0.168 & 0.065 & 0.156 & 2.597 & 0.01 \\
\hline \multicolumn{6}{|c|}{ Intention to share knowledge and knowledge sharing behaviour } \\
\hline Intention to share knowledge & 0.05 & 0.036 & 0.084 & 1.394 & 0.165 \\
\hline \multicolumn{6}{|c|}{ Level of IT services usage and knowledge sharing behaviour } \\
\hline 1. (Constant) & 0.764 & 0.044 & - & 17.417 & .000 \\
\hline Level of IT services usage & 0.055 & 0.014 & 0.239 & 4.053 & .000 \\
\hline
\end{tabular}

$\mathrm{B}$, coefficients represent the independent contributions of each independent variable to the prediction of the dependent variable; SE, standard error; Beta, coefficients reflect effects for standardised predictors; $t, t$-value measure the relative strength of prediction; Sig., significance. 
Regression results in Table 5 showed that the relationship between the level of IT services usage and knowledge sharing behaviour of lawyers in the Ibadan metropolis showed a positive correlation (0.239), which was significant at $p<0.05$. Therefore, the null hypothesis was rejected.

\section{Summary of results from test of hypotheses}

The summary from the results of the hypotheses test showed that the null hypotheses tested for hypothesis one and hypothesis five were not rejected, and were thus supported. Table 6 also shows that the null hypothesis 2, hypothesis 3 , hypothesis 4 and hypothesis 6 were supported. These were tested for the following purposes, namely to establish:

- the relationship between expected associations and attitude towards knowledge sharing

- the expected contributions and attitude towards knowledge sharing

- the attitude towards knowledge sharing and actual knowledge sharing behaviour

- the level of IT use and actual knowledge sharing behaviour.

\section{Structural model results}

Figure 2 presents the results of the study based on the research model adopted. It shows that expected associations had the greatest influence on the lawyers' attitudes towards knowledge sharing.

\section{Discussion of findings Expected rewards}

An interesting finding in this study is the expected rewards variable, as this is a factor that affects knowledge sharing amongst lawyers in the surveyed law firms. Although King and Iyoha (2008) emphasised that there had to be something that motivated the employees willingness to share their knowledge for the benefit of the organisation, stating that if the employees were not motivated, their knowledge may never be shared with others. This study discovered that expected reward was not one of the factors that motivated lawyers in Ibadan to share their knowledge within their law firms. King
TABLE 6: Hypothesis results summary.

\begin{tabular}{lll}
\hline Structural path & $\begin{array}{l}\text { Standardised } \\
\text { coefficients }\end{array}$ & Hypothesis testing \\
\hline Expected rewards $\rightarrow$ Attitude to KS & 0.058 & Not supported \\
Expected associations $\rightarrow$ Attitude to KS & $0.540^{* * *}$ & Supported \\
Expected contributions $\rightarrow$ Attitude to KS & $0.478^{* * *}$ & Supported \\
Attitude to KS $\rightarrow$ Intention to KS & $0.156^{* *}$ & Supported \\
Intention to KS $\rightarrow$ Actual KS behaviour & 0.084 & Not supported \\
Level of IT usage $\rightarrow$ Actual KS behaviour & $0.239^{* * *}$ & Supported \\
\hline
\end{tabular}

$\mathrm{KS}$, knowledge sharing.

${ }^{*} p<0.05 ;{ }^{* *} p<0.01 ;{ }^{* * *} p<0.001$

and Iyoha noted that workers willingly shared knowledge with the hope of getting rewards either from the person they are sharing their knowledge with or from the organisation. But this study observed no significant relationship between expected rewards and attitudes towards knowledge sharing behaviour of the lawyers. Gottschalk et al. (2005) established that rewards had a significant impact on knowledge sharing. The framework of Sanghani (2009) also emphasised providing incentives and rewards for knowledge sharing, whilst Ipe (2003) acknowledged the effect of rewards and incentives as a contributing factor that may influence employees' attitudes to share knowledge within an organisation. He also noted that a way to motivate people to capture knowledge is to reward them for doing so, by providing the knowledge sharers with some compensation for sharing their knowledge. The findings of this study, concerning rewards, did not agree with all these propositions about the relationship between the effect of rewards and knowledge sharing amongst lawyers in Ibadan. It did however concur with the findings of Bock and Kim (2002) that the employees' beliefs about expected rewards were negatively related to their attitudes to knowledge sharing. Bock and Kim tried to find a reasonable explanation for this by insisting that rewards have a punitive effect that break off relations and may undermine intrinsic motivation.

\section{Expected associations}

Gottschalk et al. (2005) observed that lawyers' attitudes towards associations were of less importance to their knowledge sharing behaviour in the law firm. This study however showed a positive and strong relationship between

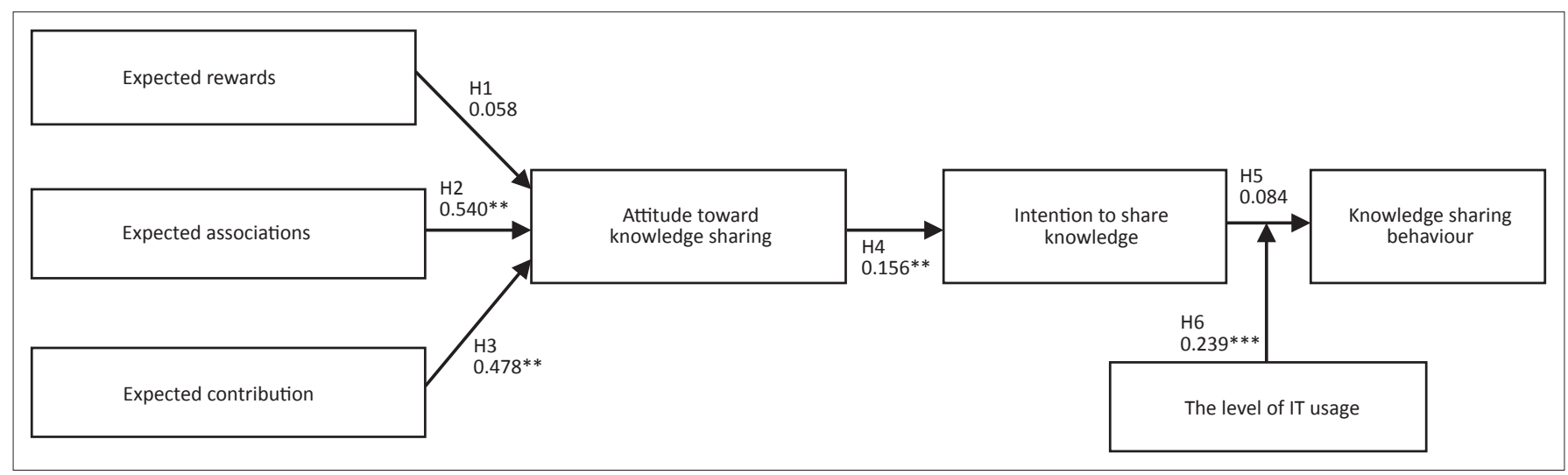

${ }^{*} p<0.05 ;{ }^{* *} p<0.01 ;{ }^{* * *} p<0.001$

FIGURE 2: Structural model results. 
expected associations of lawyers in Ibadan and their attitude to sharing knowledge. Knowledge as power is demonstrated in the increasing value attributed to individuals who possess the right kind of knowledge. If individuals perceive that power comes from the knowledge they possess, it is likely to lead to knowledge hoarding instead of knowledge sharing (Hendriks 2005). One of the external factors that influenced the motivation to share knowledge, as identified by (Ipe 2003), was the relationship between the sender and the recipient. It was noted that lawyers in Ibadan have a positive attitude towards knowledge sharing, who considered that it may strengthen the relationship between themselves and other lawyers, thus supporting Ipe's 2003 proposition.

\section{Expected contribution}

Gottschalk et al. (2005), in their study of the Incentives for Knowledge Sharing through Information Technology, noted that lawyers' attitudes towards their own contribution were the factors that mostly predicted their knowledge sharing behaviour. They also noted that, on average, a lawyer's willingness to share their knowledge with others in a law firm was influenced by their perception of their ability to contribute to the organisation by sharing that knowledge. This study corroborates this finding, as its results established that the expected contribution was significantly related with the attitude of lawyers in the Ibadan metropolis, towards their knowledge sharing. This finding also corresponds to the definition of knowledge sharing within the organisation given by many researchers. For instance, knowledge sharing between individuals is the process by which knowledge held by an individual is converted into a form that can be understood, absorbed, and used by other individuals, and that contributes to both individual and organisational learning (Ipe 2003). Knowledge sharing is important because it provides a link between the individual and the organisation by moving knowledge that resides with individuals to the organisational level, where it is converted into economic and competitive value for the organisation (Hendriks 1999). The voluntary act of sharing knowledge by an individual contributes to knowledge distribution, and the process of sharing may result in knowledge acquisition by other individuals within the organisation (Ipe 2003). Knowledge sharing between individuals, thus, results in individual learning, which in turn may contribute to organisational learning (Turner \& Minonne 2010). The ability to share knowledge, between organisational units and departments, contributes immensely to the performance of the organisation (Hendriks 2005). Thus, the motivation of workers for knowledge sharing is to exchange ideas, information and consequently knowledge to enable organisations to increase their knowledge base, improve work processes, increase productivity and help them achieve their objectives.

\section{Attitude towards knowledge sharing}

Results showed that there was a significant relationship between the attitudes of lawyers towards knowledge sharing and their intention to share knowledge. This finding agrees with Bock and Kim (2002) who found that attitudes towards knowledge sharing had a significant influence on behaviour intention. This also corroborates the finding of Ellahi and Mushtaq (2011) that confirmed that the attitudes of bloggers, towards knowledge sharing, significantly affected their intention to share knowledge in blogs. Also, the proposition of the TRA, that intention to perform behaviour is influenced by an individual's attitude toward performing the behaviour, was confirmed as attitudes towards knowledge sharing gave a positive and significant correlation with the intention to share knowledge amongst lawyers in the law firms surveyed.

\section{Intention to share knowledge}

This study determined that there was no significant relationship between the intention to share knowledge and the knowledge sharing behaviour of lawyers in the Ibadan metropolis. This deviated from the findings of Ellahi and Mushtag (2011) that the intention to share knowledge was positively related with actual knowledge sharing behaviour in blogs. Their study confirmed that one unit increase in intention to knowledge sharing will increase 0.90 units in actual knowledge sharing behaviour. The intention of bloggers, to share their knowledge, was a strong predictor of their actual knowledge sharing in blogs. The findings of this study also disagreed with the findings of Bock and Kim (2002) that an individual's actual knowledge sharing behaviour is highly correlated with the behavioural intention to share knowledge. The positive influences of attitude and intention on behaviour are, additionally, confirmed in the knowledge sharing context. It also disagreed with the TRA, based on the premise that intention is the main determinant of a person's actions or actual behaviour. This premise was not supported by the findings of this study.

\section{Level of Information Technology usage for knowledge sharing}

The relationship between the level of Information Technology (IT) services usage and knowledge sharing behaviour, of lawyers in the Ibadan metropolis, showed a positive correlation, which was significant. Ojo and Grand (2009) established that more than half of the lawyers in Botswana select IT moderately for knowledge sharing. Sanghani (2009) emphasised the importance of information technology for knowledge sharing, and noted that proper knowledge sharing was unthinkable without the appropriate technology, stating that Information Systems help the organisation manage and leverage knowledge systematically and actively. It should be noted however that only email and GSM services were being used by most of the lawyers in the Ibadan metropolis for knowledge sharing. The other IT services listed were either not being used at all or were being used by very few of them. This finding agreed with Gottschalk et al. (2005) that user satisfaction and user-friendly systems were very important when attempting to motivate lawyers to use and share knowledge via an IT system. 


\section{Implications and future studies}

This study contributes to the prevailing literature, providing empirical data on the knowledge sharing attitudes of lawyers in the Ibadan metropolis. Whilst expected associations and expected contributions were related to the lawyers' attitudes to knowledge sharing, expected rewards was not. It is recommended that law firms in Ibadan should incorporate avenues for knowledge sharing amongst lawyers, which may be routine or periodical. Regular conferences could be organised to espouse recent developments in the legal profession and opportunities given to lawyers to share ideas. Provision should be made for organisational knowledge repositories, where knowledge sources may be stored and consulted when needed. IT infrastructure and services that encourage effective knowledge sharing may, additionally, be adopted. Only Global System for Mobile communication services and email were predominantly used by the lawyers for knowledge sharing, out of a variety of IT services available that could encourage effective knowledge sharing. Law firms are also encouraged to send their lawyers for occasional relevant training. Further studies may be carried out to unravel other factors that could influence knowledge sharing, apart from those investigated in this study. Also, the influence of socio-demographic factors on knowledge sharing could be determined. It may also be necessary to measure the level of IT usage with more diverse types of Information System for knowledge sharing, in respect to other professions, and other research models of knowledge sharing could be applied to carry out future studies.

\section{Acknowledgements Competing interests}

The authors declare that they have no financial or personal relationship(s) which may have inappropriately influenced them in writing this paper.

\section{Authors' contributions}

W.M.O. (University of Ibadan) was involved in the design and data analysis aspects of the study and wrote the manuscript. I.N.E. (University of Ibadan), was involved in the design and was responsible for data collection and analysis.

\section{References}

Agbonlahor, R.O., 2005, 'Utilisation and Attitude of Higher Institution lecturers in Nigerian Universities towards Information Technology, Doctoral degree, Dept. of Information Science, Africa Regional Centre for Information Science, University of Ibadan, Nigeria.

Aiken, L.R. (2000). Psychological Testing and Assessment, 10th edn., Allyn and Bacon, Boston, MA.
Ajzen, I. \& Fishbein, M., 1980, Understanding attitudes and predicting social behaviour, Prentice-Hall, Englewood Cliffs, NJ.

Argote, L. \& Ingram, P. 2000, 'Knowledge transfer: A basis for competitive advantage in firms', Organizational Behaviour and Human Decision Processes 82(1), 150-169. http://dx.doi.org/10.1006/obhd.2000.2893

Bircham, H., 2003, 'The impact of question structure when sharing knowledge', Electronic Journal of Knowledge Management 1(2), 17-24.

Bock, G.W. \& Kim, Y.G., 2002, 'Breaking the Myths of Rewards: An Exploratory Study of Attitudes about Knowledge Sharing', Information Resource Management Journa 15(2), 14-21. http://dx.doi.org/10.4018/irmj.2002040102

Chua, A. 2003, 'Knowledge Management System Architecture: A Bridge Between Knowledge Management Consultants and Technologists', International Journal of Information Management (24)1, 87-98.

Davenport, T.H. \& Prusak, L., 1998, Working Knowledge: How Organizations Manage What They Know, Harvard Business School Press, Boston, MA.

Davis, F.D., Bagozzi, R.P. \& Warshaw, P.R., 1992, Extrinsic and Intrinsic Motivation to Use Computers in the Workplace, Journal of Applied Social Psychology 22, 11111132. http://dx.doi.org/10.1111/j.1559-1816.1992.tb00945.x

Eiseman, J., 2007, 'Creating Intranet Applications for Knowledge Sharing within Law Firms', Law and Technology Resources for Legal Professionals, viewed 16 February 2011, from http://www.llrx.com/authors/1099

Ellahi, A.A. \& Mushtaq, R., 2011, 'Probing Factors Affecting Knowledge Sharing Behaviour of Pakistani Bloggers', The Electronic Journal on Information Systems in Developing Countries 45(6), 1-14.

Global Law Firm Knowledge Management Survey Report, 2002, viewed 17 February 2011, from http://www.virtuallawjournal.net/?nodeid=32\&lang=en

Gottschalk, P., Brekke, K. \& Pedersen, H.C., 2005, 'Incentives for Knowledge Sharing through Information Technology in Law Firms' in Virtual Law Journal, viewed 17 February 2011, from http://www.virtuallawjournal.net/?nodeid=32\&lang=en

Grant, R.B., 1996, 'Towards a knowledge-based theory of the firm', Strategic Management Journal, vol. 17 (Winter Special Issue), 109-122.

Gupta, A.K., \& Govindarajan, V., 2000, 'Knowledge flows within multinational corporations' Strategic Management Journal 21, 473-496. http://dx.doi. org/10.1002/(SICI)1097-0266(200004)21:4<473::AID-SMJ84>3.0.CO;2-I

Hendriks, P., 1999, 'Why share knowledge? The influence of ICT on the motivation for knowledge sharing', Knowledge and Process Management, 6(2), 91-100 http:// dx.doi.org/10.1002/(SICI)1099-1441(199906)6:2<91::AID-KPM54>3.0.CO;2-M

Hendriks, P.H.J., 2005, 'Book Review: Knowledge Management in Organizations: A Critical Introduction', Management Learning 36(4), 535-553, viewed 12 December 2011, from http://mlq.sagepub.com/content/36/4/535

Ipe, M., 2003, 'Knowledge Sharing in Organizations: A Conceptual Framework', Human Resource Development Review 2(4), 337-359, viewed 12 July 2011 from, http:// hrd.sagepub.com/content/2/4/337

Joseph, M., Firestone, J.M. \& McElroy, M.W., 2005, 'Doing Knowledge Management' The Learning Organization Journal 12(2), viewed 24 September 2010, from http:// www.emeraldinsight.com/10.1108/0969647051

King, O.A. \& lyoha, G.E., 2008, 'Improving knowledge sharing capabilities of organizations: a case study of ReStral Nigeria Limited', Masters thesis, Blekinge Institute of Technology, Sweden.

Ojo, R.R. \& Grand, B., 2011, 'An Analysis of the Extent of IT Acceptance and Use for Knowledge Management in Botswana Law Organizations', Infotrends: An International Journal of Information and Knowledge Management 1(1), 27-37.

Ogunmoye, E.M., 2008, 'A Survey of the Attitude of Students towards Online Education in South-Western Nigerian Universities', Masters project, Africa Regional Centre for Information Science, University of Ibadan, Nigeria.

Ryu, S., Hee-Ho, S. \& Han, I., 2003, 'Knowledge sharing behaviour of physicians in hospitals', Expert Systems with Applications 25, 113-122. http://dx.doi. org/10.1016/S0957-4174(03)00011-3

Sanghani, P., 2009, 'Knowledge Management Implementation: Holistic Framework Based on Indian Study', Association for Information Systems (AIS) Electronic Library (AISeL), viewed 18 August 2011, from http://aisel.aisnet.org/pacis2009/69

Schulz, M. \& Klugmann, M. (2005), 'Creating a culture of knowledge sharing in law firms', Professional Knowledge Management, vol. 3782, pp. 386-391, Lecture Notes Artificial Intelligence (LNAI) Series, Springer Verlag, Berlin.

Senge, P., 2007, 'On sharing knowledge', The Gurteen Knowledge, viewed 14 November 2010, from http://www.gurteen.com/gurteen/gurteen.nsf/id/X00035A9E/

Turner, G. \& Minonne, C., 2010, 'Measuring the Effects of Knowledge Management Practices', Electronic Journal of Knowledge Management 8(1), 161-170, viewed 12 December 2010, from www.ejkm com

Venkatesh, V., Morris, M.G., Davis, G.B. \& Davis, E.D., 2003, 'User acceptance of information technology: Towards a unified view', MIS Quarterly 27(3), 425-478. 